\title{
Heme: a versatile signaling molecule controlling the activities of diverse regulators ranging from transcription factors to MAP kinases
}

\author{
Sarah M Mense ${ }^{1}$, Li Zhang ${ }^{1}$ \\ ${ }^{1}$ Department of Environmental Health Sciences, Columbia University, Mailman School of Public Health, 60 Haven Avenue, B-106, \\ New York, NY 10032, USA
}

Heme (iron protoporphyrin IX) is an essential molecule for numerous living organisms. Not only does it serve as a prosthetic group in enzymes, it also acts as a signaling molecule that controls diverse molecular and cellular processes ranging from signal transduction to protein complex assembly. Deficient heme synthesis or function impacts the hematopoietic, hepatic and nervous systems in humans. Recent studies have revealed a series of heme-regulated transcription factors and signal transducers including Hap1, a heme-activated transcription factor that mediates the effects of oxygen on gene transcription in the yeast Saccharomyces cerevisiae; Bach1, a transcriptional repressor that is negatively regulated by heme in mammalian cells; IRR, an iron regulatory protein that mediates the iron-dependant regulation of heme synthesis in the bacterium Bradyrhizobium japonicum; and heme-regulated inhibitor, an eucaryotic initiation factor $2 \alpha$ kinase that coordinates protein synthesis with heme availability in reticulocytes. In this review, we summarize the current knowledge about how heme controls the activity of these transcriptional regulators and signal transducers, and discuss diseases associated with defective heme synthesis, degradation and function.

Cell Research (2006) 16:681-692. doi:10.1038/sj.cr.7310086; published online 8 August 2006

Keywords: heme signaling, oxygen sensing, Hap1, Bach1, HRI, IRR

\section{Introduction}

Heme (iron protoporphyrin IX) is a tetrapyrrole containing a central iron ion [1]. Many living organisms ranging from bacteria to humans synthesize and use heme [1-4]. Heme biosynthesis in yeast and humans requires eight enzymes [3]. The first of these enzymes is located in the mitochondria as are the last three (Figure 1, Table 1) [1, 3, 4]. The remaining four enzymes involved in heme synthesis are localized in the cytosol $[1,3,4]$. The control of heme biosynthesis is complex and is dependent on multiple factors, including cell type and the availability of substrates [5-7]. Heme synthesis requires the key precursor 5-aminolevulinic acid (ALA) and two substrates, oxygen and ferrous iron $\left(\mathrm{Fe}^{2+}\right)$ (Figure 1, Table 1) $[1,3,7]$. The availability of

Correspondence: Li Zhang

Tel/Fax: +1-212-781-1038;

E-mail: 1z2115@columbia.edu each of these molecules may be limiting and may dictate the rate of heme synthesis, under certain circumstances [7]. For example, in yeast, heme synthesis is under the control of oxygen level $[3,5,8]$. Oxygen is not only required for the two steps that use it as a substrate, but its level also determines the activity of ferrochelatase, the last enzyme involved in heme synthesis (Figure 1) [8]. In mammalian erythroid cells, the availability of $\mathrm{Fe}^{2+}$ may be limiting [1, $9,10]$, and ferrochelatase activity likely dictates the rate of heme synthesis. In non-erythroid cells, particularly in hepatic cells, however, the availability of ALA is limiting [1]. Thus, the synthesis of ALA, catalyzed by ALA synthase (ALAS, Figure 1), is the rate-limiting and rate-determining step in heme synthesis $[1,10]$. Endogenously synthesized heme, as well as internalized exogenous heme, can serve diverse intracellular functions, e.g., as a prosthetic group in enzymes and protein complexes or as a signaling molecule for diverse regulatory processes (Figure 1) [11-13].

Heme plays critical roles in oxygen sensing and utilization in aerobic organisms and is indispensable for 


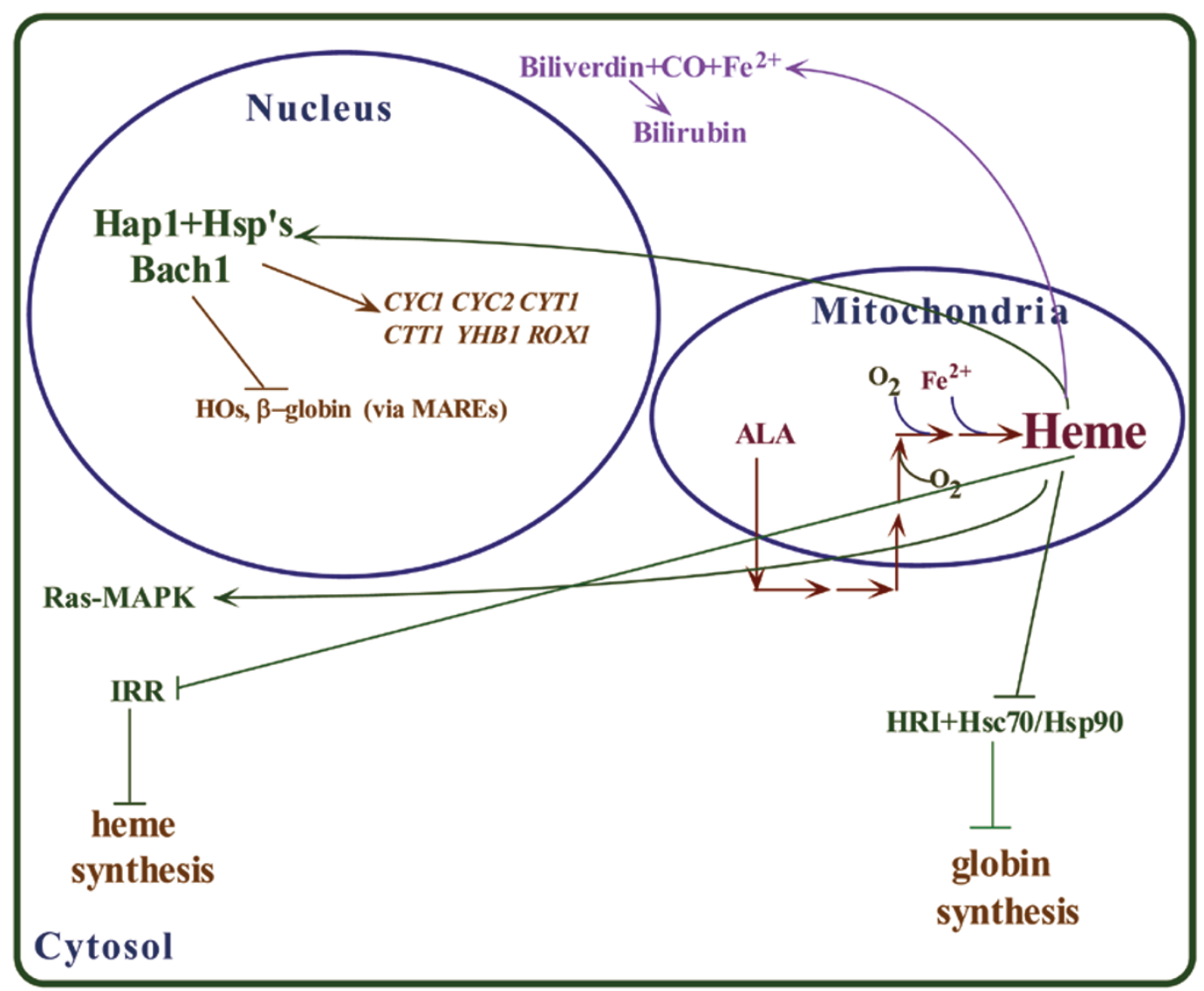

Figure 1 Heme directly regulates numerous cellular and molecular processes. In humans, heme is synthesized by eight enzymes and heme synthesis requires the key precursor ALA, oxygen and ferrous iron $\left(\mathrm{Fe}^{2+}\right)$. Heme carries out diverse functions. Heme regulates the Ras-MAPK signaling pathway. Heme also interacts with transcription factors in the nucleus to regulate the expression of various genes. In yeast, the transcription factor Hap1, in a multi-chaperone complex containing Hsp90 and Hsp70 and cochaperones, regulates the expression of $C Y C 1, C Y C 2, C Y T 1, C T T 1, Y H B 1$ and ROX1. In mammalian cells, Bach1 regulates the transcription of genes that contain MAREs in their regulatory sequences such as those that encode the HOs and $\beta$-globins. Heme regulates the activity of HRI, which interacts with Hsp90 and Hsc70. Under heme-sufficient conditions, HRI is inactivated and globin synthesis is permitted to continue. In the bacterium B. japonicum, heme interacts with IRR, and under heme-sufficient conditions, IRR is rapidly degraded, preventing it from inhibiting heme synthesis. Note that in B. japonicum, no compartmentalization of nucleus, cytosol and mitochondrion exist. In mammals, the $\mathrm{HO}$ enzymes break down heme into biliverdin, $\mathrm{CO}$ and $\mathrm{Fe}^{2+}$. Biliverdin is then converted to bilirubin by biliverdin reductase.

Table 1 A list of heme-regulated signal transducers and transcriptional regulators

\begin{tabular}{llllll}
\hline Name & Function & Heme effect & Heme binding & Interacting partners & Role of partners \\
Hap1 & Transcriptional activator & Postitive & HRMs & Hsp90 & Activation by heme \\
& & & & Hsp70, Ydj1, Sro9 & $\begin{array}{l}\text { Repression during heme deficiency } \\
\text { HRI }\end{array}$ \\
& EIF2 kinase & Negative & HRMs & Hsp90, Hsc70 & $\begin{array}{l}\text { Maturation and activation during } \\
\text { heme deficiency }\end{array}$ \\
Bach1 & Transcriptional repressor & Negative & HRMs & Maf proteins & Partner for MARE binding \\
IRR & Translation inhibitor & Negative & HRM & Ferrochelatase & Inhibition \\
\hline
\end{tabular}

many fundamental biological processes [11-14]. Heme is essential for the transport and storage of oxygen, the generation of cellular energy by respiration, the synthesis and degradation of sterols, lipids and neurotransmitters and for controlling oxidative damage. Heme serves as a prosthetic group in proteins and enzymes that sense, transport or use 
oxygen. For example, heme is essential for the formation of hemoglobin, myoglobin and cytochrome complexes [12, 15]. Heme is critical for the proper functioning of various enzyme systems including catalases, cyclooxygenases and nitric oxide synthases $[15,16]$.

Remarkably, heme directly regulates various molecular and cellular processes involved in oxygen sensing and utilization, including transcription, translation, protein translocation and protein assembly [11-14]. Heme directly controls many biological processes such as erythropoiesis, neurogenesis, cell growth and cell differentiation [11-14, 17-20]. In mammals, heme is required for the proper functioning and differentiation of many types of cells, including erythroid, hepatic and nerve cells [11-14]. As such, heme has been shown to control the activities of a variety of signal transducers and transcriptional regulators [17-20]. These include the iron regulatory protein (IRR) in the bacterium Bradyrhizobium japonicum [21], the yeast Saccharomyces cerevisiae transcriptional regulator, the heme activator protein Hap1 [14], the mammalian transcriptional repressor Bach1 [22], the heme-regulated inhibitor (HRI) kinase [23] and components of the Ras-MAPK signaling pathway (Figure 1, Table 1) [17]. In this review, we aim to summarize the current knowledge of the molecular mechanisms by which heme controls the activities of these diverse signal transducers and regulators. We also outline the diseases associated with the dysregulation of heme level.

\section{The yeast transcriptional activator Hapl acts as a key mediator of heme signaling}

Yeasts such as $S$. cerevisiae are facultative aerobes. When adequate oxygen is available this type of yeast respires; however, under oxygen-deficient conditions, it supports its energy needs by fermentation. S. cerevisiae cells sense and respond to changing oxygen levels by differentially expressing numerous genes [6, 24-27]. In $S$. cerevisiae, heme directly mediates the effects of oxygen on gene transcription through the heme activator protein Hap1 [6, 14, 25, 27]. Yeast cells grown under aerobic conditions synthesize heme in their mitochondria, and heme mediates oxygen regulation of many genes. Hap1 is a key regulator of heme signaling in yeast, and activation of Hap 1 is stringently controlled by heme [14]. Hap1 activation increases with heme concentration, and maximum Hap1 activation is reached at micromolar heme concentrations. Heme activates Hap1 in the nucleus, allowing Hap1 to bind the upstream activation sequences and promote the transcription of many genes encoding functions important for respiration and for the control of oxidative damage [14, $25,27]$. Hap1-activated genes include those for cytochrome c-iso-1 (CYC1), cytochrome $c$-iso-2 (CYC2), cytochrome $c 1(C Y T 1)$, catalase $(C T T 1)$ and flavohemoglobin $(Y H B 1)$
(Figure 1) [6, 14, 24, 25, 27]. The transcription of $R O X 1$, a repressor of genes required for anaerobic growth, is regulated by Hap1 as well (Figure 1) [6, 14, 25, 27].

Studies have revealed that Hap1 contains several important functional elements and that heme regulation of Hap1 involves the regulation of DNA-binding and transcriptionactivating activities of Hap1 (Figure 2A) [14, 28-31]. The C6 zinc cluster motif, which is located near the N-terminus, and the dimerization domain mediate Hap1 DNA binding, while the seven heme-responsive motifs (HRMs) and three repression modules (RPMs) are responsible for coupling heme regulation with Hap1 activation (Figure 2, Table 1) [14, 29, 31-34]. Hap1 transcriptional activation is conferred via the acidic activation domain near the $\mathrm{C}$-terminus of Hap1 [35]. Hap1 activity is strictly controlled by a twotiered regulatory mechanism $[14,31,34,36,37]$. The repression of Hap1 in the absence of heme is mediated by the three RPMs, which promote the formation of a higher order Hap1 complex, containing the molecular chaperones and co-chaperones Hsp90, Hsp70, Sro9 and Ydj1 [28, 31, 36]. This Hap1 multichaperone complex acts to control transcription in response to heme [14, 29, 30, 34]. Hap1 has seven HRMs that can bind heme and mediate heme activation of Hap1 [29]. HRMs are short sequence motifs that contain Cys residues [14, 21, 29, 38, 39] (Figure 2B). Not all of the seven HRMs are equally important for the activation of Hap1 [40, 41]. Experimental evidence suggests that HRM7 is critical for heme activation of Hap1, while HRMs 1-6 appear to play auxiliary roles and are dispensable for Hap1 activation by heme [40, 41]. Heme promotes Hap 1 transcriptional activity by enhancing the association of Hsp90 to the Hap1-Hsp70-Ydj1-Sro9 multichaperone complex, causing conformational changes in the complex $[14,29,31,34,36,37,40,41]$. Subsequently, the complex transforms into a conformationally different complex that has a high affinity for DNA binding and is transcriptionally active [14, 29, 31, 34, 36, 37, 40, 41].

\section{IRR coordinates heme synthesis under iron limitation in B. japonicum}

Iron is an essential element for most living organisms and is required for numerous cellular processes, including electron transfer, oxygen metabolism and signal transduction. Iron is directly involved in the heme biosynthetic pathway; the last step of heme synthesis requires the insertion of ferrous iron into protoporphyrin IX by the enzyme ferrochelatase (Figure 1). In aerobic environments, iron is present in the insoluble ferric form, and its availability may be limiting $[21,42,43]$.

In the bacterium $B$. japonicum, IRR meditates the irondependent regulation of heme synthesis [21, 42, 43]. In $B$. japonicum, iron is often the limiting nutrient in the heme 
A
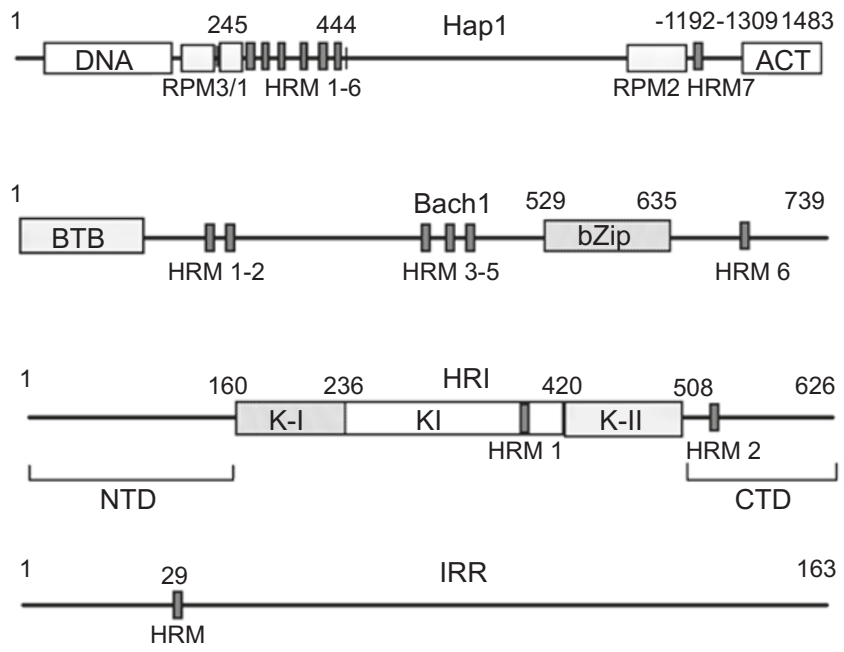

B

\begin{tabular}{llll} 
Hap1 & & \multicolumn{3}{c}{ Bach1 } \\
278 & KCPINH & 223 & LCPKYR \\
297 & KCPVDH & 298 & QCPTEK \\
323 & RCPVDH & 434 & ECPWLG \\
347 & RCPVDH & 460 & NCPFIS \\
389 & KCPVDH & 491 & PCPYAC \\
414 & RCPIDH & 645 & DCPLSF \\
1192 & KCPVYQ & & \\
& & HRI & \\
IRR & & 409 & ACPYVM \\
28 & GCPWHD & 551 & RCPVQA
\end{tabular}

Figure 2 (A) Domain structures of the heme-regulated proteins Hap1, HRI, IRR and Bach1. Hap1 contains a DNA-binding domain (DNA) that mediates DNA-binding and an activation domain (ACT) that confers transcriptional activation. The three RPMs and seven HRMs of Hap1 couple heme regulation with Hap1 activation. Bach1 contains six HRMs responsible for heme binding and two functional domains, BTB/POZ (BTB) and bZip, which regulate protein interaction and DNA binding, respectively. HRI contains the NTD, a K-I, a KI with one HRM, a K-II, and the CTD with one HRM. IRR contains a single HRM. (B) Sequences of HRMs from Hap1, HRI, IRR and Bach1. The indicated HRMs are from the $S$. cerevisiae heme activator protein Hap1, human eucaryotic translation initiation factor 2-alpha kinase 1 (HRI), the B. japonicum iron response regulator (IRR) and the human basic leucine zipper transcription factor (Bach1). The cysteine-proline dipeptide in each of the HRMs is bold.

synthesis pathway, and under iron-deficient conditions, all steps of the heme synthesis pathway cannot be completed [43]. As a result, heme precursors such as protoporphyrin and other porphyrins accumulate in the cell, and when aggregated, these porphyrins are toxic [44]. In order to prevent the accumulation of toxic porphyrins in the cell during iron deficiency, iron regulatory proteins link iron availability to heme synthesis $[21,42,45]$. IRR modulates heme synthesis by controlling the expression level of hemB, the gene that encodes the heme biosynthetic enzyme ALA dehydratase [44, 46-48]. Loss of function mutations in the IRR gene are sufficient to uncouple heme synthesis from iron availability, resulting in porphyrin accumulation and cytotoxicity [21, 42, 45]. Notably, recent findings indicate that in B. japonicum, IRR allows the sensing of iron level via heme synthesis to regulate iron homeostasis and metabolism [49]. In addition, it was also shown that IRR plays a role in mediating the control of heme synthesis in response to oxidative stress [50].

IRR is a conditionally stable protein, whose stability depends on iron status (Figure 2) [21, 42]. In iron-deficient conditions, IRR accumulates, while in iron-replete conditions, IRR is rapidly degraded [21, 42]. IRR responds to iron availability via the status of protoporphyrin and heme at the site of heme synthesis [21, 43]. During iron sufficiency, IRR is inactivated by ferrochelatase and then subjected to heme-dependent degradation [45]. When iron is limited, protoporphyrin relieves the inhibition of IRR by ferrochelatase by promoting protein dissociation $[42,43]$. The addition of exogenous heme is sufficient to produce IRR destabilization, while in heme synthesis mutant strains, IRR persists even under iron-sufficient conditions [21, 42, 45]. IRR proteins harboring mutations in the heme-binding region are stable even in the presence of iron, suggesting that the destabilization of IRR by iron involves the binding of heme to an HRM within the IRR protein (Figure 2) [42]. Ferric and ferrous heme bind different regions within IRR, and both are needed to induce IRR degradation [42]. Experimental evidence indicates that both ferric and ferrous iron participate in a single process leading to the degradation of IRR [42].

The HRI kinase inhibits eucaryotic initiation factor $2 \alpha$ during heme deficiency in mammalian reticulocytes

During mammalian erythropoiesis, late-stage erythroblasts enucleate and become reticulocytes [51]. These immature erythroid cells, reticulocytes, mature over the course of a few days and during this process they complete the synthesis of hemoglobin, and other erythroid-specific proteins [51, 52]. Given their enhanced need to synthesize hemoglobin, reticulocytes have an increased requirement for iron so that they are able to support their very high capacity to synthesize heme $[52,53]$.

Heme is required for the synthesis of $\beta$ - and $\alpha$-globin chains into hemoglobin by reticulocytes, and the aggregation of unassembled globin chains is toxic to the cell [54]. HRI coordinates protein synthesis in reticulocytes to heme availability [23, 55-57]. It is a member of a family of protein kinases that regulate the initiation of protein synthesis in eucaryotic cells. Under heme-deficient conditions, HRI inhibits protein synthesis at the level of translational initia- 
tion, thereby preventing the accumulation of unassembled globin chains and their toxic effects $[52,54]$. During heme deficiency, HRI is activated, permitting it to phosphorylate serine 51 of the $\alpha$-subunit of the eIF2 [52, 54, 58]. Phosphorylation of eIF $2 \alpha$ prevents it from being recycled for protein translation and results in the inhibition of protein synthesis $[52,54]$.

HRI is a multidomain protein composed of five structural domains (Figure 2), namely, the N-terminal domain (NTD), the kinase I domain (K-I), the kinase insertion domain (KI), the kinase II domain (K-II) and the C-terminal domain (CTD) [56, 59-61]. The catalytic domain of HRI is divided in two halves, one on each side of the KI domain, and activation of HRI is thought to involve bringing residues on each of these two halves of the catalytic domain into close proximity [23, 56, 59-61]. Two HRMs are present in HRI, one in the KI domain and the other in the CTD [23, 56, 59-61]. The heme binding site in the KI domain is thought to reversibly bind heme and to play a role in the coordination of HRI activity with changes in heme concentration [61]. The second heme binding site, contained in the NTD without an HRM, consists of a stably bound heme that co-purifies with HRI [59, 62]. This heme-binding domain appears to be the active center for nitric acid- and carbon monoxide-induced activity of HRI; NO enhances HRI activation, while $\mathrm{CO}$ suppresses HRI activation [63]. The isolated NTD stably binds heme but does not display any kinase activity. The CTD domain does not bind to heme, although it contains an HRM motif [61].

The molecular chaperones Hsp90 and Hsc70 are critical for HRI maturation and heme regulation (Table 1) [54, 64-68]. Nascent HRI is not active during heme deficiency or heme sufficiency in reticulocytes [69]. Immature HRI interacts with Hsp90 and Hsc70, and after a maturation phase, a population of heme deficiency-activatable mature HRI appears [54, 70]. However, this mature competent HRI continues to interact with the chaperones $[54,69,71]$. The interaction between HRI and the chaperones is thought to be important for maintaining HRI in a mature state that is capable of activation under heme deficiency $[67,69]$. Upon activation in heme-deficient conditions, HRI gains autokinase activity and eIF2 $\alpha$ kinase activity $[54,69,71]$. The transition from inactive to active HRI requires the actions of the Hsp90 and Hsc70 chaperone machinery [71]. Once the transformation is complete, HRI no longer associates with the chaperones [69].

The transcriptional repression activity of Bach1 is negatively regulated by heme in mammals

Bach1, a basic leucine zipper protein, is a heme-regulated transcriptional repressor found in mammals $[72,73]$. The activity of Bach1 is modulated by heme [72, 73]. Bach1 forms heterodimers with proteins in the Maf-related oncoprotein family (MafK, MafF, MafG) (Figure 1, Table 1). The Bach1-Maf heterodimers bind to the Maf recognition element (MARE) in the regulatory region of its target genes [72, 74-77]. MAREs are found in the regulatory regions of genes involved in heme metabolism, such as oxidative stress response genes, globin genes, heme oxygenase-1 and erythroid-specific ALAS [72, 78-81]. It has been suggested that the transcription of genes possessing MAREs is regulated via a balance between transcriptional activation and repression $[22,80]$. Under normal conditions, when expressed with small Maf proteins, Bach1 is located in the nucleus [77]. However, under conditions with increased heme levels, Bach1 is exported from the nucleus and is localized in the cytoplasm [77].

Bach1 has two functional domains: BTB/POZ and bZip, which regulate protein interaction and DNA binding, respectively (Figure 2) $[22,73]$. Studies have revealed that Bach1 possesses six HRM (CP) motifs (see Figure 2A and $2 \mathrm{~B})$ that are essential for heme-mediated regulation $[22$, 82]. Two HRM (CP) motifs are downstream of the BTB/ POZ domain, three are upstream of the bZip domain and one is downstream of the bZip domain $[22,77]$. Heme binding by Bach1 is dependent on the HRM (CP) motifs, and there is evidence suggesting that heme binding to the HRM (CP) motifs of Bach1 is cooperative [22]. No single HRM (CP) motif is indispensable for heme regulation of Bach1, indicating that there is functional redundancy among the HRM (CP) motifs [22]. The three heme binding motifs of Bach1 function as heme-activated nuclear export signals, suggesting that Bach1-mediated gene expression is at least partially mediated by the regulation of Bach1 subcellular localization [77, 83, 84].

Heme negatively regulates the transcriptional repressor function of Bach1 by inhibiting the DNA-binding ability of the Bach1-MafK heterodimer [22, 80]. Concentrations of heme as low as $0.03 \mu \mathrm{M}$ result in a slight but reproducible inhibition of Bach1-MafK DNA binding, while $1 \mu \mathrm{M}$ heme concentrations cause almost complete inhibition of Bach1-MafK DNA-binding activity [22]. Nrf2 is distantly related to Bach1 and binds similar DNA sequences as Bach1 when in a heterodimer with Maf proteins [73, 80]. However, Nrf2 activates transcription in genes with MAREs in their regulatory regions, and the DNA-binding ability of Nrf2 is not inhibited by heme [22]. The switch of the Maf dimerization partner from Bach1 to Nrf2 is a key event in the transition from gene repression to gene activation $[73,77]$.

\section{Heme regulates the Ras-MAPK signaling pathway}

Heme is critical for neuronal differentiation in rat pheochromocytoma (PC12) cells, a model system for studying 
neuronal differentiation $[17,85]$. Heme deficiency induced by succinyl acetone, a potent inhibitor of ALA dehydratase, the second enzyme involved in heme synthesis, greatly reduces the number and length of NGF-induced neurites [17, 86]. The effect of succinyl acetone on neurite outgrowth is reversed by the addition of heme, suggesting that heme deficiency is responsible for the effect of succinyl acetone on neurite outgrowth [17]. At the molecular level, heme deficiency inactivates the Ras-ERK1/2 signaling pathway induced by NGF [17]. Moreover, heme deficiency selectively causes NGF-differentiated PC12 cells to undergo caspase activation and apoptosis [20]. Differentiated PC12 cells are more vulnerable to heme deficiency than undifferentiated PC12 cells, suggesting a role for NGF signaling in producing the observed effects [20].

Heme shortage interferes with neuronal gene expression $[17,20]$. Under normal heme concentrations, NGF induces the expression of neuron-specific genes in PC12 cells, many of which encode signal transducers and important structural functions $[87,88]$. Heme deficiency alters the expression of important signaling components of the NGF signaling pathway such as Ras, MEKK1, p38 MAPK, p53 and c-myc $[17,20]$. Upon inhibition of heme synthesis, the induction of these genes is abolished, which may explain why heme deficiency interferes with neuronal differentiation [17, 20]. Genes with important structural functions in neurons whose expression is modulated by heme include survival motor neuron protein, synaptic vesicle protein (SVOP), nicotinic acetylcholine receptor, dopa decarboxylase, neural cell adhesion molecule, neuropeptide $\mathrm{Y}$ precursor and neurofilament protein $[17,20]$. In addition, inhibition of heme synthesis suppresses the activation of the RasERK1/2 signaling pathway but activates JNK in the late stages of NGF induction [17, 20]. CREB, a downstream target of the Ras-ERK1/2 signaling pathway that controls the expression of many neuronal genes [89], is inactivated by heme deficiency as well $[17,20]$.

The effects of heme are cell-type specific. Studies indicate that while heme promotes differentiation in $\mathrm{PC} 12$ neurons and K562 erythroid cells, it promotes cell growth and cell cycle progression in HeLa cells [17, 18, 20, 90, 91]. In K562 cells, heme initiates changes in the expression of various genes that control numerous processes, such as cell cycle, Ras signaling, chromatin structure, protein folding and splicing [19]. Heme may promote erythroid differentiation by promoting the expression of $\mathrm{p} 18$ and $\mathrm{p} 21$, negative regulators of the cell cycle and suppressing the expression of cyclin D1 [19]. In HeLa cells, the induction of negative regulators of the cell cycle, such as p53 and p21, and the inhibition of positive regulators, such as $\mathrm{Cdc} 2$ and $\mathrm{Cdk} 4$, caused by heme deficiency ultimately leads to cell cycle arrest and apoptosis [90].
Dysregulation of heme levels can cause serious diseases

Given that heme is essential to numerous fundamental biological processes, it is not surprising that dysregulation of heme levels results in various diseases [4]. In humans defective heme synthesis has been implicated in diseases including anemia and porphyrias [1, 4, 92-100]. Partially defective ALAS results in sideroblastic anemia, while defects in any of the other enzymes involved in heme biosynthesis results in porphyria [1, 92-100]. Porphyrias may be inherited or caused by the intake of chemicals that inhibit the enzymes involved in heme synthesis [9295]. For example, lead inhibits ALA dehydratase and ferrochelatase activity [101]. The effect of lead on heme synthesis may be related to the encephalopathy caused by lead poisoning [101]. Porphyrias are associated with skin lesions, neuropathy and hepatic dysfunction [1, 92-100]. Neurological manifestations of porphyrias include those associated with disturbances of the CNS, such as anxiety, confusion and depression, and of the autonomic nervous system, such as abdominal pain, vomiting, hypertension and tachycardia [1, 92-100].

Heme deficiency may be a factor in the mitochondrial and neuronal decay observed in aging and Alzheimer's disease [102-107]. Heme shortage prevents the assembly of complex IV, the terminal complex of the electron transport chain [108]. The four complexes of the electron transport chain are essential for ATP production by oxidative phosphorylation and are the main source of free radicals that contribute to mitochondrial damage associated with aging and various diseases [109-113]. In heme-deficient conditions, the activity and protein content of complex IV decreases by more than $95 \%$ [7]. Complex II and cytochrome $c$ are affected by heme deficiency to a lesser extent, while complexes I and III remain intact during heme shortage [7]. The activity of complex IV undergoes a $30 \%$ to $50 \%$ reduction with aging and in Alzheimer's patients; however, the reason for this decline remains unclear $[102,114,115]$. It is possible that the amount of heme-a decreases with age, and since complex IV relies on heme-a, its activity declines as well $[102,108]$. Studies of heme-a in Alzheimer's patients found that heme-a decreased $22 \%$, while heme-b and heme-c remained unchanged compared to healthy controls of the same age [7].

The amount of heme-a present in the cell determines the rate of complex IV assembly [102, 108, 116]. Three main conditions inhibit the production of heme-a: hypoxia, low heme production and pantothenate deficiency [117, 118]. The vulnerability of complex IV to heme deficiency may be due to its use of heme-a [7, 102, 108]. Complex I contains only Fe-S clusters, complex II and catalase contain only heme-b and complex III contains both heme-b and heme-c $[7,102,108]$. One explanation for the loss of complex IV 
in heme deficiency is that maturation of proto-heme to heme-a is more complex than the maturation of proto-heme to heme-b or c [7]. The maturation of heme-a is rate limiting, and during heme shortage, less heme-a is formed due to the heme-a pathway's low affinity for heme relative to the heme-b and heme-c pathways [7]. Another possibility is that oxidative stress associated with heme deficiency damages the heme-a maturation pathway [7].

Just as heme deficiency has detrimental consequences, excess free heme is associated with separate problems. Excess free heme can bring about severe cell and tissue damage $[10,15,119,120]$. Hemin, the oxidized form of heme, causes hemolysis by inducing potassium loss and swelling of red cell membranes, destroying the ability of erythrocytes to maintain cation gradients [15]. There are two phases of the heme-induced hemolytic process: massive $\mathrm{K}^{+}$loss followed by depletion of glutathione and ATP, and massive hemoglobin loss [121]. In addition, hemin changes the conformation of cytoskeletal proteins and causes altered membrane stability and red cell lesions $[15$, 122]. Hemolysis during sickle cell anemia and $\beta$-thalassemia is most likely a result of a greater interaction of free heme with red cell membranes and subsequent oxidative membrane damage [15]. In support of this idea is the finding that the amount of hemin incorporated into the cell membranes of cells of sickle cell anemia and $\beta$-thalassemia is higher than the amount of hemin incorporated into normal cell membranes [15]. Heme is also thought to play a role in the removal of aged red cells from the circulation via hemolysis. The level of hemin in the membrane is age-dependant such that old cells accumulate more hemin than do young red cells [15].

Another mechanism of heme toxicity is via heme-induced oxidative stress [123]. Heme catalyzes the formation of reactive oxygen species (ROS), and heme released from intracellular hemoproteins is an important source of redox active iron [15]. ROS created in the presence of heme are capable of damaging proteins, lipids and DNA [119, 124127]. Heme is a lipophilic molecule that can easily cross cell membranes and gain entry to cells [15]. In vitro and in vivo, cells accumulate exogenous heme. This results in the synergistic amplification of damage and cytotoxicity of oxidants present in the cell $[128,129]$.

Heme's pro-oxidant activities toward DNA, carbohydrates, proteins and lipids have been demonstrated in vitro, but the pro-oxidant roles of heme in vivo remain unclear. Hemin aggregates in cell membranes where it promotes oxidation, leading to membrane damage and cell death [10, 130, 131]. Heme oxidizes membrane-bound, while hemin catalyzes the degradation of proteins to small peptide fragments $[132,133]$. In the presence of oxygen and $\beta$-MSH hemin creates nicks in isolated plasmid DNA $[10,134]$. Heme propagates the peroxidation of groups in membrane, serum or cytosolic proteins. Protein oxidation by heme depends on the nature of protein binding and heme's affinity for the particular protein, and may result in non-reducible covalent cross-linking or protein fragmentation [120, 131].

Heme-mediated inflammation has been implicated in the pathogenesis of several diseases, including arteriosclerosis, renal failure and heart transplant failure $[15,119,123$, 135]. Release of heme can bring about local inflammatory reactions that may result in renal failure [136]. In a model of kidney failure, heme proteins get trapped in the glomeruli and subsequently accumulate in the kidney [136, 137]. Elevated heme levels are capable of acting in the pro-inflammatory manner. Exposure of endothelial cells to heme promotes the expression of intercellular adhesion molecule 1, vascular adhesion molecule 1 and endothelial leukocyte adhesion molecules (E-selectin) $[138,139]$. Once activated, these endothelial adhesion molecules recruit leukocytes [15]. Heme is thought to stimulate the expression of pro-inflammatory molecules via heme-mediated ROS production. These ROS activate redox-reactive transcription factors and signaling pathways such as $\mathrm{NF}-\kappa \mathrm{B}, \mathrm{AP}-1$ and SP-1 [138-140].

\section{The oxidant potential of heme is neutralized by multiple heme-binding proteins}

Heme-binding proteins counteract the oxidizing effects of heme by forming complexes with heme or by scavenging free redox-active iron released after heme catabolism [15]. Hemopexin, albumin, $\alpha-1-$ microglobulin, and reduced glutathione are the most well-known heme-binding molecules $[15,141]$. Hemopexin is an intravascular protein that binds free heme with a very high affinity and protects against heme toxicity in vitro [141-143]. This protein protects cells without hemopexin receptors by binding heme and preventing the destructive effects of non-specific heme uptake. Hemopexin-heme complexes bind hemopexin receptors, which are taken up by the cell via an endocytotic mechanism $[142,144]$. Heme is then released from hemopexin into the cell and degraded. Hemopexin stays inside the endocytotic vesicle and is released outside the cell $[145,146]$. Albumin is another heme-binding protein present in the blood that can bind free heme from hemorrhage or dying cells. Albumin has a lower affinity for binding heme than does hemopexin [147]. Interestingly, a $23 \mathrm{kDa}$ heme-binding protein, termed HBP23, is shown to be expressed in the cytosol of the liver, kidney, spleen, small intestine and heart cells [148, 149]. Another $21 \mathrm{kDa}$ heme-binding protein, termed $222 \mathrm{HBP}$, is shown to be induced by heme in mouse erythroleukemia cells [148, 150]. These proteins may play important roles in heme metabolism in diverse cells. 
Ultimately, heme is degraded. In mammals, two heme oxygenase (HO) enzymes, HO-1 and HO-2, have been identified, confirmed and characterized [123, 151, 152]. A third gene, HO-3, appears to be a pseudogene derived from HO-2 [153]. HOs are the rate-limiting enzymes in heme degradation. $\mathrm{HO}$ degrades heme to generate ferrous iron, $\mathrm{CO}$ and biliverdin [154-156] (Figure 1). Biliverdin is subsequently converted to bilirubin by biliverdin reductase [154]. The HO system is no longer considered only in the context of heme catabolism since heme metabolites are biologically active molecules. Traditionally, bilirubin was viewed as a neurotoxin and of clinical significance only in relation to neonatal jaundice. Now, bilirubin is seen as a potent antioxidant that is able to protect neurons against free radical damage [10, 157-161].

$\mathrm{HO}-1$ expression is inducible, while HO-2 expression is constitutive [162]. The expression of each gene differs by cell type, tissue distribution and regulation [163]. The regulation of HO-1 expression in mammalian cells is very complex. HO- 1 is induced by many factors, such as hypoxia, hydrogen peroxide, heavy metals, heme and depletion of cellular glutathione [162, 164]. The regulation of HO-1 expression by these factors is not only cell type-dependent but also species-dependent [162, 164]. For example, hypoxia induces HO-1 expression in rodent, bovine and monkey cells, but represses HO-1 expression in several human cell lines, including lung cancer A549 cells, umbilical vein endothelial cells and glioblastoma cells [72, 165-170]. A detailed discussion of HO-1 regulation can be found in an excellent review written by Sikorki et al. [162].

\section{Perspective}

It is increasingly clear that heme regulates the actions of numerous transcription factors and signal transducers in addition to its structural roles in proteins. Here we have reviewed recent findings about several heme-regulated transcription factors and signal transducers, including Hap1, Bach1, IRR and HRI. In mammals, heme controls many processes critical for important systems such as the hematopoietic, hepatic and nervous systems. It is highly likely that many more heme-regulated transcription factors and signal transducers operate in various mammalian cells. It is also likely that heme is associated with more diseases in humans than those currently known, such as porphyrias and anemias. Heme is essential for the survival and proper functioning of most, if not all, cells, so that mutants with greatly defective heme synthesis or function do not exist. However, moderate changes in heme level or function may be found to be associated with many diseases, including neurological diseases such as Alzheimer's disease.

\section{References}

1 Anderson KE, Sassa S, Bishop DF, Desnick RJ. Disorders of heme biosynthesis: X-linked sideroblastic anemia and the porphyrias. In: Scriver CR, Beaudt AL, Sly WS, et al, eds. The metabolic and molecular bases of inherited disease. New York: The McGraw-Hill Companies Inc., 2001:2991-3062.

2 O'Brian MR, Thony-Meyer L. Biochemistry, regulation and genomics of haem biosynthesis in prokaryotes. Adv Microb Physiol 2002; 46:257-318.

3 Labbe-Bois R, Labbe P. Tetrapyrrole and heme biosynthesis in the yeast Sacchromyces cerevisiae. In: Dailey HA, ed. Biosynthesis of heme and cholorophylls. New York: Green Pub. Associates and Wiley-Interscience, 1990:235-285.

4 Wijayanti N, Katz N, Immenschuh S. Biology of heme in health and disease. Curr Med Chem 2004; 11:981-986.

5 Mattoon J, Lancashire W, Sanders H, et al. Oxygen and catabolite regulation of hemoprotein biosynthesis in the yeast Saccharomyces cerevisiae. In: Caughey WJ, ed. Biosynthesis of heme and cholorophylls. New York: Academic Press, 1979:421-435.

6 Poyton RO. Models for oxygen sensing in yeast: implications for oxygen-regulated gene expression in higher eucaryotes. Respir Physiol 1999; 115:119-133.

7 Atamna H, Walter PB, Ames BN. The role of heme and ironsulfur clusters in mitochondrial biogenesis, maintenance, and decay with age. Arch Biochem Biophys 2002; 397:345-353.

8 Hon T, Dodd A, Dirmeier R, et al. A mechanism of oxygen sensing in yeast: multiple oxygen-responsive steps in the heme biosynthetic pathway affect Hap1 activity. J Biol Chem 2003; 278:50771-50780.

9 Ponka P. Tissue-specific regulation of iron metabolism and heme synthesis: distinct control mechanisms in erythroid cells. Blood 1997; 89:1-25.

10 Ryter SW, Tyrrell RM. The heme synthesis and degradation pathways: role in oxidant sensitivity. Heme oxygenase has both pro- and antioxidant properties. Free Radical Biol Med 2000; 28:289-309.

11 Padmanaban G, Venkateswar V, Rangarajan PN. Haem as a multifunctional regulator. Trends Biochem Sci 1989; 14:492-496.

12 Sassa S, Nagai T. The role of heme in gene expression. Int J Hematol 1996; 63:167-178.

13 Ponka P. Cell biology of heme. Am J Med Sci 1999; 318:241256.

14 Zhang L, Hach A. Molecular mechanism of heme signaling in yeast: the transcriptional activator Hap1 serves as the key mediator. Cell Mol Life Sci 1999; 56:415-426.

15 Kumar S, Bandyopadhyay U. Free heme toxicity and its detoxification systems in human. Toxicol Lett 2005; 157:175-188.

16 Rodgers KR. Heme-based sensors in biological systems. Curr Opin Chem Biol 1999; 3:158-167.

17 Zhu Y, Hon T, Ye W, Zhang L. Heme deficiency interferes with the Ras-mitogen-activated protein kinase signaling pathway and expression of a subset of neuronal genes. Cell Growth Differ 2002; 13:431-439.

18 Zhu Y, Hon T, Zhang L. Heme initiates changes in the expression of a wide array of genes during the early erythroid differentiation stage. Biochem Biophys Res Commun 1999; 258:87-93.

19 Zhu Y, Lee HC, Zhang L. An examination of heme action in gene expression: heme and heme deficiency affect the expression of 
diverse genes in erythroid $\mathrm{k} 562$ and neuronal PC12 cells. DNA Cell Biol 2002; 21:333-346.

20 Sengupta A, Hon T, Zhang L. Heme deficiency suppresses the expression of key neuronal genes and causes neuronal cell death. Brain Res Mol Brain Res 2005; 137:23-30.

21 Qi Z, Hamza I, O'Brian MR. Heme is an effector molecule for iron-dependent degradation of the bacterial iron response regulator (Irr) protein. Proc Natl Acad Sci USA 1999; 96:1305613061.

22 Ogawa K, Sun J, Taketani S, et al. Heme mediates derepression of Maf recognition element through direct binding to transcription repressor Bach1. EMBO J 2001; 20:2835-2843.

23 Chen JJ, London IM. Regulation of protein synthesis by hemeregulated eIF-2 alpha kinase. Trends Biochem Sci 1995; 20:105108.

24 Kwast KE, Burke PV, Poyton RO. Oxygen sensing and the transcriptional regulation of oxygen-responsive genes in yeast. J Exp Biol 1998; 201:1177-1195.

25 Zitomer RS, Lowry CV. Regulation of gene expression by oxygen in Saccharomyces cerevisiae. Microbiol Rev 1992; 56:1-11.

26 Bunn HF, Poyton RO. Oxygen sensing and molecular adaptation to hypoxia. Physiol Rev 1996; 76:839-885.

27 Zitomer RS, Carrico P, Deckert J. Regulation of hypoxic gene expression in yeast. Kidney Int 1997; 51:507-513.

28 Zhang L, Hach A, Wang C. Molecular mechanism governing heme signaling in yeast: a higher-order complex mediates heme regulation of the transcriptional activator HAP1. Mol Cell Biol 1998; 18:3819-3828.

29 Zhang L, Guarente L. Heme binds to a short sequence that serves a regulatory function in diverse proteins. EMBO J 1995; 14:313320.

30 Hon T, Hach A, Tamalis D, et al. The yeast heme-responsive transcriptional activator Hap1 is a preexisting dimer in the absence of heme. J Biol Chem 1999; 274:22770-22774.

31 Hon T, Lee HC, Hach A, et al. The Hsp70-Ydj1lmolecular chaperone represses the activity of the heme activator protein Hap1 in the absence of heme. Mol Cell Biol 2001; 21:7923-7932.

32 King DA, Zhang L, Guarente L, Marmorstein R. Structure of a HAP1/DNA complex reveals dramatically asymmetric DNA binding by a homodimeric protein. Nat Struct Biol 1999; 6:6471.

33 Zhang L, Guarente L. The C6 zinc cluster dictates asymmetric binding by HAP1. EMBO J 1996; 15:4676-4681.

34 Lee HC, Hon T, Lan C, Zhang L. Structural environment dictates the biological significance of heme-responsive motifs and the role of Hsp90 in the activation of the heme activator protein Hap1. Mol Cell Biol 2003; 23:5857-5866.

35 Pfeifer K, Kim KS, Kogan S, Guarente L. Functional dissection and sequence of yeast HAP1 activator. Cell 1989; 56:291-301.

36 Lan C, Lee HC, Tang S, Zhang L. A novel mode of chaperone action: heme activation of hap1 by enhanced association of Hsp90 with the repressed Hsp70-Hap1 complex. J Biol Chem 2004; 279:27607-27612.

37 Lee HC, Hon T, Zhang L. The molecular chaperone Hsp90 mediates heme activation of the yeast transcriptional activator Hap1. J Biol Chem 2002; 277:7430-7437.

38 Lathrop JT, Timko MP. Regulation by heme of mitochondrial protein transport through a conserved amino acid motif. Science 1993; 259:522-525.

39 Steiner H, Kispal G, Zollner A, et al. Heme binding to a conserved
Cys-Pro-Val motif is crucial for the catalytic function of mitochondrial heme lyases. J Biol Chem 1996; 271:32605-32611.

40 Hach A, Hon T, Zhang L. A new class of repression modules is critical for heme regulation of the yeast transcriptional activator Hap1. Mol Cell Biol 1999; 19:4324-4333.

41 Hon T, Hach A, Lee HC, et al. Functional analysis of heme regulatory elements of the transcriptional activator Hap1. Biochem Biophys Res Commun 2000; 273:584-591.

42 Yang J, Ishimori K, O'Brian MR. Two heme binding sites are involved in the regulated degradation of the bacterial iron response regulator (Irr) protein. J Biol Chem 2005; 280:7671-7676.

43 Gao T, O'Brian MR. Iron-dependent cytochrome c1 expression is mediated by the status of heme in Bradyrhizobium japonicum. J Bacteriol 2005; 187:5084-5089.

44 Hamza I, Chauhan S, Hassett R, O'Brian MR. The bacterial irr protein is required for coordination of heme biosynthesis with iron availability. J Biol Chem 1998; 273:21669-21674.

45 Qi Z, O'Brian MR. Interaction between the bacterial iron response regulator and ferrochelatase mediates genetic control of heme biosynthesis. Mol Cell 2002; 9:155-162.

46 Hentze MW, Kuhn LC. Molecular control of vertebrate iron metabolism: mRNA-based regulatory circuits operated by iron, nitric oxide, and oxidative stress. Proc Natl Acad Sci USA 1996; 93:8175-8182.

47 Rouault TA, Klausner RD. Iron-sulfur clusters as biosensors of oxidants and iron. Trends Biochem Sci 1996; 21:174-177.

48 Chauhan S, Titus DE, O'Brian MR. Metals control activity and expression of the heme biosynthesis enzyme delta-aminolevulinic acid dehydratase in Bradyrhizobium japonicum. J Bacteriol 1997; 179:5516-5520.

49 Yang J, Sangwan I, Lindemann A, et al. Bradyrhizobium japonicum senses iron through the status of haem to regulate iron homeostasis and metabolism. Mol Microbiol 2006; 60:427-437.

50 Yang J, Panek HR, O’Brian MR. Oxidative stress promotes degradation of the Irr protein to regulate haem biosynthesis in Bradyrhizobium japonicum. Mol Microbiol 2006; 60:209-218.

51 Koury MJ, Koury ST, Kopsombut P, Bondurant MC. In vitro maturation of nascent reticulocytes to erythrocytes. Blood 2005; 105:2168-2174.

52 Han AP, Fleming MD, Chen JJ. Heme-regulated eIF2alpha kinase modifies the phenotypic severity of murine models of erythropoietic protoporphyria and beta-thalassemia. J Clin Invest 2005; 115:1562-1570

53 Ponka P, Sheftel AD, Zhang AS. Iron targeting to mitochondria in erythroid cells. Biochem Soc Trans 2002; 30:735-738.

54 Yun BG, Matts JA, Matts RL. Interdomain interactions regulate the activation of the heme-regulated eIF 2 alpha kinase. Biochim Biophys Acta 2005; 1725:174-181.

55 Wek RC. eIF-2 kinases: regulators of general and gene-specific translation initiation. Trends Biochem Sci 1994; 19:491-496.

56 Chen JJ, Throop MS, Gehrke L, et al. Cloning of the cDNA of the heme-regulated eukaryotic initiation factor 2 alpha (eIF-2 alpha) kinase of rabbit reticulocytes: homology to yeast $\mathrm{GCN} 2$ protein kinase and human double-stranded-RNA-dependent eIF-2 alpha kinase. Proc Natl Acad Sci USA 1991; 88:7729-7733.

57 de Haro C, Mendez R, Santoyo J. The eIF-2alpha kinases and the control of protein synthesis. FASEB J 1996; 10:1378-1387.

58 Colthurst DR, Campbell DG, Proud CG. Structure and regulation of eukaryotic initiation factor eIF-2. Sequence of the site in the alpha subunit phosphorylated by the haem-controlled repres- 
sor and by the double-stranded RNA-activated inhibitor. Eur J Biochem 1987; 166:357-363.

59 Uma S, Matts RL, Guo Y, et al. The N-terminal region of the heme-regulated eIF2alpha kinase is an autonomous heme binding domain. Eur J Biochem 2000; 267:498-506.

60 Bauer BN, Rafie-Kolpin M, Lu L, et al. Multiple autophosphorylation is essential for the formation of the active and stable homodimer of heme-regulated eIF2alpha kinase. Biochemistry 2001; 40:11543-11551.

61 Rafie-Kolpin M, Chefalo PJ, Hussain Z, et al. Two heme-binding domains of heme-regulated eukaryotic initiation factor-2alpha kinase. $\mathrm{N}$ terminus and kinase insertion. J Biol Chem 2000; 275:5171-5178.

62 Chefalo PJ, Oh J, Rafie-Kolpin M, et al. Heme-regulated eIF2alpha kinase purifies as a hemoprotein. Eur J Biochem 1998; 258:820-830.

63 Uma S, Yun BG, Matts RL. The heme-regulated eukaryotic initiation factor 2alpha kinase. A potential regulatory target for control of protein synthesis by diffusible gases. J Biol Chem 2001; 276:14875-14883.

64 Matts RL, Hurst R. Evidence for the association of the hemeregulated eIF-2 alpha kinase with the $90-\mathrm{kDa}$ heat shock protein in rabbit reticulocyte lysate in situ. J Biol Chem 1989; 264:1554215547.

$65 \mathrm{Xu} \mathrm{Z}$, Pal JK, Thulasiraman V, et al. The role of the $90-\mathrm{kDa}$ heat-shock protein and its associated cohorts in stabilizing the heme-regulated eIF-2alpha kinase in reticulocyte lysates during heat stress. Eur J Biochem 1997; 246:461-470.

66 Matts RL, Hurst R. The relationship between protein synthesis and heat shock proteins levels in rabbit reticulocyte lysates. J Biol Chem 1992; 267:18168-18174.

67 Shao J, Grammatikakis N, Scroggins BT, et al. Hsp90 regulates $\mathrm{p} 50$ (cdc37) function during the biogenesis of the active conformation of the heme-regulated eIF2 alpha kinase. J Biol Chem 2001; 276:206-214.

68 Thulasiraman V, Yun BG, Uma S, et al. Differential inhibition of Hsc70 activities by two Hsc70-binding peptides. Biochemistry 2002; 41:3742-3753.

69 Uma S, Hartson SD, Chen JJ, Matts RL. Hsp90 is obligatory for the heme-regulated eIF-2alpha kinase to acquire and maintain an activable conformation. J Biol Chem 1997; 272:11648-11656.

70 Shao J, Hartson SD, Matts RL. Evidence that protein phosphatase 5 functions to negatively modulate the maturation of the Hsp90dependent heme-regulated eIF2alpha kinase. Biochemistry 2002; 41:6770-6779.

71 Uma S, Thulasiraman V, Matts RL. Dual role for Hsc70 in the biogenesis and regulation of the heme-regulated kinase of the alpha subunit of eukaryotic translation initiation factor 2. Mol Cell Biol 1999; 19:5861-5871.

72 Kitamuro T, Takahashi K, Ogawa K, et al. Bach1 functions as a hypoxia-inducible repressor for the heme oxygenase-1 gene in human cells. J Biol Chem 2003; 278:9125-9133.

73 Ishikawa M, Numazawa S, Yoshida T. Redox regulation of the transcriptional repressor Bach1. Free Radical Biol Med 2005; 38:1344-1352.

74 Igarashi K, Itoh K, Hayashi N, et al. Conditional expression of the ubiquitous transcription factor MafK induces erythroleukemia cell differentiation. Proc Natl Acad Sci USA 1995; 92:74457449.

75 Igarashi $\mathrm{K}$, Itoh $\mathrm{K}$, Motohashi $\mathrm{H}$, et al. Activity and expression of murine small Maf family protein MafK. J Biol Chem 1995; 270:7615-7624.

76 Igarashi K, Kataoka K, Itoh K, et al. Regulation of transcription by dimerization of erythroid factor NF-E2 p45 with small Maf proteins. Nature 1994; 367:568-572.

77 Yamasaki C, Tashiro S, Nishito Y, et al. Dynamic cytoplasmic anchoring of the transcription factor Bach1 by intracellular hyaluronic acid binding protein IHABP. J Biochem (Tokyo) 2005; 137:287-296.

78 Ishii T, Itoh K, Takahashi S, et al. Transcription factor Nrf2 coordinately regulates a group of oxidative stress-inducible genes in macrophages. J Biol Chem 2000; 275:16023-16029.

79 Hoshino H, Igarashi K. Expression of the oxidative stress-regulated transcription factor bach2 in differentiating neuronal cells. J Biochem (Tokyo) 2002; 132:427-431.

80 Sun J, Hoshino H, Takaku K, et al. Hemoprotein Bach1 regulates enhancer availability of heme oxygenase-1 gene. EMBO J 2002; 21:5216-5224.

81 Sun J, Muto A, Hoshino H, et al. The promoter of mouse transcription repressor bach1 is regulated by $\mathrm{Sp} 1$ and trans-activated by Bach1. J Biochem (Tokyo) 2001; 130:385-392.

82 Oyake $\mathrm{T}$, Itoh $\mathrm{K}$, Motohashi $\mathrm{H}$, et al. Bach proteins belong to a novel family of BTB-basic leucine zipper transcription factors that interact with MafK and regulate transcription through the NF-E2 site. Mol Cell Biol 1996; 16:6083-6095.

83 Suzuki H, Tashiro S, Hira S, et al. Heme regulates gene expression by triggering Crm1-dependent nuclear export of Bach1. EMBO J 2004; 23:2544-2553.

84 Suzuki H, Tashiro S, Sun J, et al. Cadmium induces nuclear export of Bach1, a transcriptional repressor of heme oxygenase-1 gene. J Biol Chem 2003; 278:49246-49253.

85 Greene LA, Tischler AS. Establishment of a noradrenergic clonal line of rat adrenal pheochromocytoma cells which respond to nerve growth factor. Proc Natl Acad Sci USA 1976; 73:24242428.

86 De Matteis F, Marks GS. The effect of $N$-methylprotoporphyrin and succinyl-acetone on the regulation of heme biosynthesis in chicken hepatocytes in culture. FEBS Lett 1983; 159:127-131.

87 Gage FH, Buzsaki G, Armstrong DM. NGF-dependent sprouting and regeneration in the hippocampus. Prog Brain Res 1990; 83:357-370.

88 Alleva E, Petruzzi S, Cirulli F, Aloe L. NGF regulatory role in stress and coping of rodents and humans. Pharmacol Biochem Behav 1996; 54:65-72.

89 Shaywitz AJ, Greenberg ME. CREB: a stimulus-induced transcription factor activated by a diverse array of extracellular signals. Annu Rev Biochem 1999; 68:821-861.

90 Ye W, Zhang L. Heme controls the expression of cell cycle regulators and cell growth in HeLa cells. Biochem Biophys Res Commun 2004; 315:546-554.

91 Ye W, Zhang L. Heme deficiency causes apoptosis but does not increase ROS generation in HeLa cells. Biochem Biophys Res Commun 2004; 319:1065-1071.

92 Scarlett YV, Brenner DA. Porphyrias. J Clin Gastroenterol 1998; 27:192-198.

93 Scarlett YV, Brenner DA, Bloomer JR. Hepatic porphyrias. Clin Liver Dis 1998; 2:77-102, vi.

94 Grandchamp B. Acute intermittent porphyria. Semin Liver Dis 1998; 18:17-24.

95 Meyer UA, Schuurmans MM, Lindberg RL. Acute porphyrias: 
pathogenesis of neurological manifestations. Semin Liver Dis 1998; 18:43-52.

96 Moore MR. Historical introduction to porphyrins and porphyrias. In: Dailey HA, ed. Biosynthesis of heme and cholorophylls. New York: Green Pub. Associates and Wiley-Interscience, 1990:154.

97 Tenhunen R, Mustajoki P. Acute porphyria: treatment with heme. Semin Liver Dis 1998; 18:53-55.

98 Kappas A, Sassa S, Galbraith RA, Nordmann Y. The porphyrias. In: Scriver CR, Beaudt AL, Sly WS, Valle D, eds. The metabolic and molecular bases of inherited disease. New York: The McGraw-Hill Companies Inc., 1995:2103-2160.

99 Desnick RJ, Glass IA, Xu W, et al. Molecular genetics of congenital erythropoietic porphyria. Semin Liver Dis 1998; 18:77-84.

100 Nordmann Y, Deybach J-C. Human hereditary porphyrias. In: Dailey HA, ed. Biosynthesis of heme and cholorophylls. New York: Green Pub. Associates and Wiley-Interscience, 1990:491541.

101 Bressler JP, Goldstein GW. Mechanisms of lead neurotoxicity. Biochem Pharmacol 1991; 41:479-484.

102 Atamna H. Heme, iron, and the mitochondrial decay of ageing. Ageing Res Rev 2004; 3:303-318.

103 Schipper HM. Heme oxygenase-1: role in brain aging and neurodegeneration. Exp Gerontol 2000; 35:821-830.

104Schipper HM, Chertkow H, Mehindate K, et al. Evaluation of heme oxygenase-1 as a systemic biological marker of sporadic AD. Neurology 2000; 54:1297-1304.

105 Schipper HM, Cisse S, Stopa EG. Expression of heme oxygenase-1 in the senescent and Alzheimer-diseased brain. Ann Neurol $1995 ; 37: 758-768$.

106Smith MA, Nunomura A, Zhu X, et al. Metabolic, metallic, and mitotic sources of oxidative stress in Alzheimer disease. Antioxid Redox Signal 2000; 2:413-420.

107Kimpara T, Takeda A, Yamaguchi T, et al. Increased bilirubins and their derivatives in cerebrospinal fluid in Alzheimer's disease. Neurobiol Aging 2000; 21:551-54.

108 Atamna H, Liu J, Ames BN. Heme deficiency selectively interrupts assembly of mitochondrial complex IV in human fibroblasts: relevance to aging. J Biol Chem 2001; 276:4841048416.

109Cadenas E, Davies KJ. Mitochondrial free radical generation, oxidative stress, and aging. Free Radical Biol Med 2000; 29:222230.

110 Han D, Williams E, Cadenas E. Mitochondrial respiratory chaindependent generation of superoxide anion and its release into the intermembrane space. Biochem J 2001; 353:411-416.

111 Raha S, Robinson BH. Mitochondria, oxygen free radicals, disease and ageing. Trends Biochem Sci 2000; 25:502-508.

112 Albers DS, Beal MF. Mitochondrial dysfunction and oxidative stress in aging and neurodegenerative disease. J Neural Transm Suppl 2000; 59:133-154.

113 Beckman KB, Ames BN. The free radical theory of aging matures. Physiol Rev 1998; 78:547-581.

114 Parker WD Jr, Parks J, Filley CM, Kleinschmidt-DeMasters BK. Electron transport chain defects in Alzheimer's disease brain. Neurology 1994; 44:1090-1096.

115 Maurer I, Zierz S, Moller H. Evidence for a mitochondrial oxidative phosphorylation defect in brains from patients with schizophrenia. Schizophr Res 2001; 48:125-136.
116 Wielburski A, Nelson BD. Heme a induces assembly of rat liver cytochrome $c$ oxidase subunits I-III in isolated mitochondria. FEBS Lett 1984; 177:291-294.

117 Ames BN, Atamna H, Killilea DW. Mineral and vitamin deficiencies can accelerate the mitochondrial decay of aging. Mol Aspects Med 2005; 26:363-378.

118 Ames BN. Delaying the mitochondrial decay of aging. Ann NY Acad Sci 2004; 1019:406-411.

119Balla J, Balla G, Jeney V, et al. Ferriporphyrins and endothelium: a 2-edged sword-promotion of oxidation and induction of cytoprotectants. Blood 2000; 95:3442-3450.

120Jeney V, Balla J, Yachie A, et al. Pro-oxidant and cytotoxic effects of circulating heme. Blood 2002; 100:879-887.

121. Chou AC, Fitch CD. Mechanism of hemolysis induced by ferriprotoporphyrin IX. J Clin Invest 1981; 68:672-677.

122. Liu SC, Zhai S, Lawler J, Palek J. Hemin-mediated dissociation of erythrocyte membrane skeletal proteins. J Biol Chem 1985; 260:12234-12239.

123. Wagener FA, Volk HD, Willis D, et al. Different faces of the heme-heme oxygenase system in inflammation. Pharmacol Rev 2003; 55:551-571.

124. Gutteridge JM, Smith A. Antioxidant protection by haemopexin of haem-stimulated lipid peroxidation. Biochem J 1988; 256:861-865.

125. Lavrovsky Y, Song CS, Chatterjee B, Roy AK. Age-dependent increase of heme oxygenase-1 gene expression in the liver mediated by NFkappaB. Mech Ageing Dev 2000; 114:49-60.

126. Letarte PB, Lieberman K, Nagatani K, et al. Hemin: levels in experimental subarachnoid hematoma and effects on dissociated vascular smooth-muscle cells. J Neurosurg 1993; 79:252-255.

127 Wagener, Feldman E, de Witte T, Abraham NG. Heme induces the expression of adhesion molecules ICAM-1, VCAM-1, and E selectin in vascular endothelial cells. Proc Soc Exp Biol Med 1997; 216:456-463.

128Balla G, Vercellotti GM, Muller-Eberhard U, et al. Exposure of endothelial cells to free heme potentiates damage mediated by granulocytes and toxic oxygen species. Lab Invest 1991; 64:648655.

129Balla G, Jacob HS, Eaton JW, et al. Hemin: a possible physiological mediator of low density lipoprotein oxidation and endothelial injury. Arterioscler Thromb 1991; 11:1700-1711.

130 Schmitt TH, Frezzatti WA Jr, Schreier S. Hemin-induced lipid membrane disorder and increased permeability: a molecular model for the mechanism of cell lysis. Arch Biochem Biophys 1993; 307:96-103.

131 Vincent SH. Oxidative effects of heme and porphyrins on proteins and lipids. Semin Hematol 1989; 26:105-113.

132 Aft RL, Mueller GC. Hemin-mediated oxidative degradation of proteins. J Biol Chem 1984; 259:301-305.

133 Camejo G, Halberg C, Manschik-Lundin A, et al. Hemin binding and oxidation of lipoproteins in serum: mechanisms and effect on the interaction of LDL with human macrophages. J Lipid Res 1998; 39:755-766.

134Aft RL, Mueller GC. Hemin-mediated DNA strand scission. J Biol Chem 1983; 258:12069-12072.

135Van Langendonckt A, Casanas-Roux F, Dolmans MM, Donnez J. Potential involvement of hemoglobin and heme in the pathogenesis of peritoneal endometriosis. Fertil Steril 2002; 77:561-570. 
136 Nath KA, Vercellotti GM, Grande JP, et al. Heme protein-induced chronic renal inflammation: suppressive effect of induced heme oxygenase-1. Kidney Int 2001; 59:106-117.

137Nath KA, Balla J, Croatt AJ, Vercellotti GM. Heme proteinmediated renal injury: a protective role for 21 -aminosteroids in vitro and in vivo. Kidney Int 1995; 47:592-602.

138Lavrovsky Y, Schwartzman ML, Levere RD, et al. Identification of binding sites for transcription factors NF-kappa B and AP-2 in the promoter region of the human heme oxygenase 1 gene. Proc Natl Acad Sci USA 1994; 91:5987-5991.

139Shono T, Ono M, Izumi H, et al. Involvement of the transcription factor NF-kappaB in tubular morphogenesis of human microvascular endothelial cells by oxidative stress. Mol Cell Biol 1996; 16:4231-4239.

140 Wagener FA, Eggert A, Boerman OC, et al. Heme is a potent inducer of inflammation in mice and is counteracted by heme oxygenase. Blood 2001; 98:1802-1811.

141 Wagner KR, Sharp FR, Ardizzone TD, et al. Heme and iron metabolism: role in cerebral hemorrhage. J Cereb Blood Flow Metab 2003; 23:629-652.

142 Tolosano E, Altruda F. Hemopexin: structure, function, and regulation. DNA Cell Biol 2002; 21:297-306.

143 Delanghe JR, Langlois MR. Hemopexin: a review of biological aspects and the role in laboratory medicine. Clin Chim Acta 2001; 312:13-23.

144 Smith A, Hunt RC. Hemopexin joins transferrin as representative members of a distinct class of receptor-mediated endocytic transport systems. Eur J Cell Biol 1990; 53:234-245.

145 Alam J, Smith A. Receptor-mediated transport of heme by hemopexin regulates gene expression in mammalian cells. J Biol Chem 1989; 264:17637-17640.

146Smith A, Morgan WT. Hemopexin-mediated transport of heme into isolated rat hepatocytes. J Biol Chem 1981; 256:1090210909.

147 Grinberg LN, O’Brien PJ, Hrkal Z. The effects of heme-binding proteins on the peroxidative and catalatic activities of hemin. Free Radical Biol Med 1999; 27:214-219.

148Iwahara S, Satoh H, Song DX, et al. Purification, characterization, and cloning of a heme-binding protein $(23 \mathrm{kDa})$ in rat liver cytosol. Biochemistry 1995; 34:13398-13406.

149Immenschuh S, Iwahara S, Satoh $\mathrm{H}$, et al. Expression of the mRNA of heme-binding protein 23 is coordinated with that of heme oxygenase- 1 by heme and heavy metals in primary rat hepatocytes and hepatoma cells. Biochemistry 1995; 34:1340713411.

150 Taketani S, Adachi Y, Kohno H, et al. Molecular characterization of a newly identified heme-binding protein induced during differentiation of urine erythroleukemia cells. J Biol Chem 1998; 273:31388-31394.

151 McCoubrey WK, Jr., Huang TJ, Maines MD. Heme oxygenase-2 is a hemoprotein and binds heme through heme regulatory motifs that are not involved in heme catalysis. J Biol Chem 1997; 272:12568-12574.

152 Maines MD, Trakshel GM, Kutty RK. Characterization of two constitutive forms of rat liver microsomal heme oxygenase. Only one molecular species of the enzyme is inducible. J Biol Chem 1986; 261:411-419.

153 Hayashi S, Omata Y, Sakamoto H, et al. Characterization of rat heme oxygenase-3 gene. Implication of processed pseudogenes derived from heme oxygenase-2 gene. Gene 2004; 336:241250.

154Tenhunen R, Marver HS, Schmid R. Microsomal heme oxygenase. Characterization of the enzyme. J Biol Chem 1969; 244:6388-6394.

155Noguchi M, Yoshida T, Kikuchi G. Identification of the product of heme degradation catalyzed by the heme oxygenase system as biliverdin IX alpha by reversed-phase high-performance liquid chromatography. J Biochem (Tokyo) 1982; 91:1479-1483.

156Maines MD. Heme oxygenase: function, multiplicity, regulatory mechanisms, and clinical applications. FASEB J 1988; 2:25572568.

157Stocker R, Yamamoto Y, McDonagh AF, et al. Bilirubin is an antioxidant of possible physiological importance. Science 1987; 235:1043-1046.

158Baranano DE, Snyder SH. Neural roles for heme oxygenase: contrasts to nitric oxide synthase. Proc Natl Acad Sci USA 2001; 98:10996-11002.

159Nakagami T, Toyomura K, Kinoshita T, Morisawa S. A beneficial role of bile pigments as an endogenous tissue protector: anti-complement effects of biliverdin and conjugated bilirubin. Biochim Biophys Acta 1993; 1158:189-193.

160Dore S, Takahashi M, Ferris CD, et al. Bilirubin, formed by activation of heme oxygenase-2, protects neurons against oxidative stress injury. Proc Natl Acad Sci USA 1999; 96:2445-2450.

161 Llesuy SF, Tomaro ML. Heme oxygenase and oxidative stress. Evidence of involvement of bilirubin as physiological protector against oxidative damage. Biochim Biophys Acta 1994; 1223:914.

162 Sikorski EM, Hock T, Hill-Kapturczak N, Agarwal A. The story so far: Molecular regulation of the heme oxygenase-1 gene in renal injury. Am J Physiol Renal Physiol 2004; 286:F425-F441.

163 Schipper HM. Heme oxygenase expression in human central nervous system disorders. Free Radical Biol Med 2004; 37:19952011.

164 Immenschuh S, Ramadori G. Gene regulation of heme oxygenase-1 as a therapeutic target. Biochem Pharmacol 2000; 60:11211128.

165 Kacimi R, Chentoufi J, Honbo N, et al. Hypoxia differentially regulates stress proteins in cultured cardiomyocytes: role of the p38 stress-activated kinase signaling cascade, and relation to cytoprotection. Cardiovasc Res 2000; 46:139-150.

166Lee PJ, Jiang BH, Chin BY, et al. Hypoxia-inducible factor-1 mediates transcriptional activation of the heme oxygenase-1 gene in response to hypoxia. J Biol Chem 1997; 272:5375-5381.

167 Motterlini R, Foresti R, Bassi R, et al. Endothelial heme oxygenase-1 induction by hypoxia. Modulation by inducible nitric-oxide synthase and $S$-nitrosothiols. J Biol Chem 2000; 275:1361313620.

168. Shibahara S, Nakayama M, Kitamuro T, et al. Repression of heme oxygenase-1 expression as a defense strategy in humans. Exp Biol Med (Maywood) 2003; 228:472-473.

169 Takahashi S, Takahashi Y, Yoshimi T, Miura T. Oxygen tension regulates heme oxygenase-1 gene expression in mammalian cell lines. Cell Biochem Funct 1998; 16:183-193.

170 Yang ZZ, Zou AP. Transcriptional regulation of heme oxygenases by HIF-1 alpha in renal medullary interstitial cells. Am J Physiol Renal Physiol 2001; 281:F900-F908. 